\title{
Ozone protocol squares up to climate
}

\section{Europeans back efforts to amend the Montreal Protocol to address global warming.}

As climate observers fret over December's global-warming summit in Copenhagen, international ozone negotiators are quietly plugging away on a proposed amendment to the Montreal Protocol on ozone-depleting substances - one that could reshape the way governments tackle an important class of greenhouse gas.

Delegates to the protocol will meet in Port Ghalib, Egypt, on 4-8 November to discuss proposals to reduce the use of hydrofluorocarbons (HFCs), common refrigerants that were deployed to replace ozone-destroying chemicals such as chlorofluorocarbons. Although HFCs do not damage the ozone layer, some are up to 12,000 times more effective than carbon dioxide at trapping heat. Advocates of the proposals say that HFCs could be efficiently regulated under the Montreal Protocol - which has proved effective in cutting the use of ozone-depleting substances - to help slow global warming.

European Union (EU) negotiators endorsed the idea during the United Nations climate talks in Bangkok earlier this month, adding momentum to a movement led by the small island states of Mauritius and Micronesia, which are seeking aggressive action on climate change to stave off rising sea levels. Those states submitted an initial amendment to the protocol in April, followed last month by a proposal from the United States, Canada and Mexico.

Nonetheless, it is unclear whether Montreal delegates will move forward with such a decision when they meet in Egypt. European officials remain wary of letting the Montreal process get
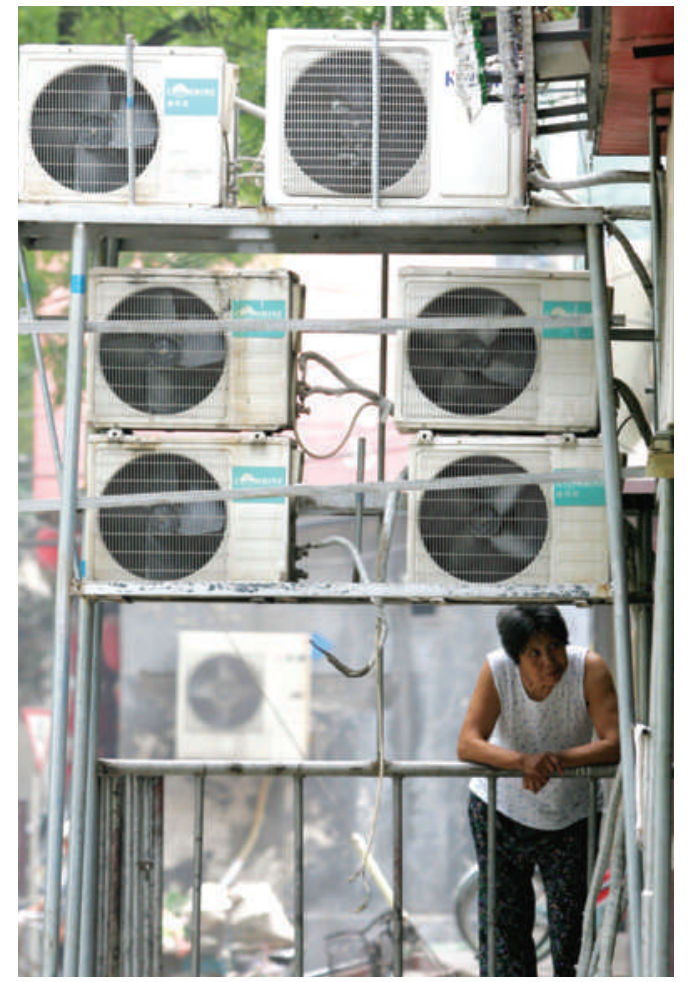

A real air con: local cooling, but global warming.

too far ahead of the Copenhagen climate talks (see 'On the global-warming front'), and the idea has yet to garner endorsement from emerging economies such as China and India, which represent the primary growth market for HFCs owing to rising demand for air conditioning.

"I could envision something that says, 'We are willing and interested in the possibility and would be prepared to take this on if so instructed," says Ana Maria Kleymeyer, Argentina's former lead negotiator on the protocol, who now works at the International Centre for Trade and Sustainable Development in Geneva, Switzerland.

Montreal delegates first ventured into global warming in 2007 when they agreed to accelerate the phase-out of hydrochlorofluorocarbons to reduce the gases' greenhouse effects. Regulating HFCs, however, would require an explicit expansion of the Montreal treaty.

Language proposed by European climate negotiators would allow their Montreal counterparts to move forward on HFCs as long as any greenhouse-gas reductions achieved by decreasing HFCs could count towards commitments under the UN climate treaty.

"The Europeans just want to make sure that whatever is done on the Montreal Protocol side is credited on the climate side," says Durwood Zaelke, president of the Institute for Governance \& Sustainable Development in Washington DC. He says one possibility is that EU negotiators in Egypt could agree to set global HFC emission standards for vehicles, consistent with current EU domestic regulations.

The European Commission says it wants to resolve how to coordinate financing, accounting and regulations between the Kyoto and Montreal treaties before moving forward. The commission is calling on a technical committee established under Montreal to analyse the proposals by the middle of 2010 .

Jeff Tollefson

\section{On the global-warming front}

As ozone negotiators look for ways to help battle global warming (see above), the international representatives who work solely on climate are inching along towards their own deal.

Last week in Luxembourg, European Union (EU) environment ministers fleshed out their negotiating position for the climate summit in Copenhagen this December, but finance ministers were unable to agree on how much money the EU will commit to developing countries for adaptation and mitigation to climate change.

The environment ministers endorsed earlier commitments to cut emissions by $20 \%$ by 2020 compared to 1990 levels, and by $30 \%$ if there is a global treaty; they also said that emissions from the aviation and maritime sectors should be curbed by $10 \%$ and $20 \%$,

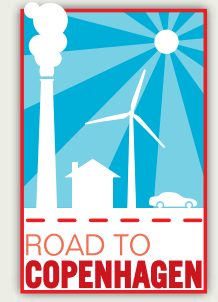

respectively, below 2005 levels by 2020.

European heads of state are expected to approve these recommendations and to tackle the issue of climate financing when they meet in Brussels this week. The European Commission has estimated that, in total, developing countries will need $€ 100$ billion (US $\$ 150$ billion) annually to begin developing low-carbon economies to cope with the impacts of climate change.

In the United States, meanwhile, Senate Democrats have begun work on a bill to curb US emissions by $20 \%$ by 2020 and by $83 \%$ by 2050 , compared with 2005 levels. The Senate Environment and Public Works Committee is hearing testimony on the bill this week, to be followed "as soon as possible" by amendments and a final vote. \section{崫} (5)

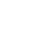

